\title{
Las correcciones de Juan Rejano. En torno a Canciones de la paz (1955)
}

\author{
Juan Rejano's Corrections. \\ Around Canciones de la paz (1955)
}

\author{
Ángel Luis Luján Atienza \\ Universidad de Castilla-La Mancha
}

\section{RESUMEN}

Este artículo trata de dar cuenta de las razones que llevaron a Juan Rejano a eliminar el libro Canciones de la paz (1955) de su primera gran recopilación, Alas de tierra (1975), y a modificarlo sustancialmente en su última suma poética, La mirada del hombre (1978). Con el análisis de las circunstancias en que nació el libro, vinculado al Movimiento Mundial por la Paz e influenciado por las consignas del PCE, y con el estudio de variantes, poemas eliminados y poemas reubicados, podemos aventurar que Rejano no se sentía cómodo con la parte más combativa del libro y con la que presentaba la faceta más sombría de la realidad contemporánea, además de que no cabía el adoctrinamiento en una escritura explícitamente dirigida a los niños.

Palabras Clave: Juan Rejano; poesía infantil; política y literatura; estudio de variantes; Canciones de la paz (1955).

\section{ABSTRACT}

The aim of this paper is to explain the reasons for Juan Rejano to have removed his book Canciones de la paz (Songs for the Peace, 1955) from his first almost complete poems collection, Alas de tierra (Wings of Earth, 1975), and to modify it in his last «collected poems», La mirada del hombre (The Man's Sight, 1978). In this paper, the circumstances under which the book was written will be analysed, these being linked to the World Movement for Peace and being deeply influenced by the P.C.E. (Spanish Communist Party) exhortations. The study of textual variants, deleted poems and new assignments in finished poems reveals that Juan Rejano feels uncomfortable with the combative voice of this part of his work as the instrument to reveal the ugliest side in contemporary life. In addition, this book, intended to be written for children, does not fit in young readers literature.

Key words: Juan Rejano; Poetry for Children; Politics and Literature; Study of Textual Variants; Canciones de la paz (Songs for the Peace, 1955). 
Juan Rejano (Puente Genil, Córdoba 1903 - Ciudad de México, 1976) ${ }^{1}$ es una de las figuras más destacadas del exilio español republicano. Además de poeta, como periodista fue fundador y director de la mítica Romance (Caudet, 1992: 115-169), de la efímera Ultramar (Caudet, 1992: 353-368; Valender, 1993) y director del suplemento cultural de El Nacional de México. Ejerció también como ensayista, conferenciante y activista político, afiliado desde joven al PCE.

A pesar de la relevancia del personaje, la obra de Rejano ha sido en general poco atendida, y su poesía en particular apenas estudiada. Contamos con los valiosos trabajos de Teresa Hernández, las dos recopilaciones de su obra (Rejano, 1988 y 2003) y la edición del libro póstumo La tarde (Rejano, 2008). Sin embargo, es significativo que en las Actas del Congreso que se le dedicó en 2002 su labor poética apenas sea glosada y que los participantes se centren en su semblanza personal o su labor como periodista. Resulta llamativo, además, que en la evocación que hace Adolfo Sánchez Vázquez, al repasar su trayectoria lírica, se olvide de Canciones de la paz (Hernández, 2002: 181). En el número monográfico que le dedica la revista Litoral solo dos son los artículos centrados en su poesía (Señales, 1980: 148-166).

\section{LA SINGULARIDAD DE CANCIONES DE LA PAZ EN LA OBRA DE REJANO}

Canciones de la paz apareció en 1955, con ilustraciones de Miguel Prieto, en la editorial España y la paz, que parece creada expresamente para este libro, pues no se encuentran más títulos de este sello. No es fácil tampoco hallar ejemplares del libro, pues no constan ni en la Biblioteca del Colegio de México, ni en la Biblioteca Nacional de México, ni en la de la UNAM, y solo aparece un ejemplar en la Biblioteca del Ateneo español de México. En España no aparecen ejemplares ni en la Biblioteca Nacional de Madrid, ni en la de la Residencia de Estudiantes, ni se recoge en el Catálogo del Patrimonio Bibliográfico Español. El ejemplar que he consultado pertenece al Pavelló de la República de la red de Bibliotecas de la Universitat de Barcelona.

Esta escasez de ejemplares va acorde con la singularidad que supone el libro en la obra de Rejano por dos razones: es el único acercamiento del autor a la literatura para niños, y es el volumen que sufre más alteraciones en los diversos proyectos de obras completas del poeta.

Para entender estos cambios y vacilaciones, que después examinaré con detalle, debemos explicar qué lugar ocupa el libro en el conjunto de la obra del autor.

\footnotetext{
${ }^{1}$ Para una visión global del autor y su obra puede verse Albornoz (1988), Hernández y García Berrio (1977), Hernández (2002, 2003 y 2008), Aznar Soler (2000), Señales de Juan Rejano (1980), Hernández de León-Portilla (2003: 301-317) y la información contenida en la página web de la Fundación Juan Rejano de Puente Genil: http://www.fundacionjuanrejano.es/ [ref. de 20 agosto 2015].
} 
Como se ha señalado repetidamente, en Rejano conviven varias estéticas: la comprometida, la intimista y la de la canción popular, que la mayoría de autores entienden como una dicotomía: «el arte menor, la canción, la copla (donde radica su tono andaluz, popular, ingenuo); y el alejandrino o el endecasílabo, la elegía, la oda, el soneto (donde encontraríamos, de un lado, su poesía civil, y del otro, su poesía más introspectiva)» (Álvarez, 1991: 17-18).

El arte menor y la canción toman, por lo general, formas de la estética popular y suelen vehicular la añoranza de la patria. Esta estética neopopularista está claramente representada e iniciada en El Genil y los olivos (1944), evocación y nostalgia del campo andaluz, continúa en El oscuro límite (1948) con la inserción intercalada de cuatro «Canciones», aparece en Constelación menor (1950) en las secciones «Córdoba del trópico. Canciones (1949)» (añadida después de la edición original), «Tres canciones antiguas» y «Nanas»; ocupa el libro entero Cantar del vencido (fechado en 1954, pero no publicado hasta 1975) y llega a su culminación en Canciones de la paz (1955), con apariciones esporádicas en libros posteriores. El verso mayor, por su parte, utilizado en géneros que van del himno heroico a la elegía subjetiva, pasando por la poesía amorosa, suele servir de cauce para la poesía más comprometida y de índole civil y heroica, bien estudiada por Hernández (2006) y Le Bigot (2006).

La situación peculiar del libro en esta encrucijada de estéticas estriba en que en él encontramos la forma menor y popular para un poemario que tiene vocación combativa y comprometida, lo que crea un primer foco de tensión y donde puede residir una de las claves de la aparente insatisfacción del autor con respecto a un poemario que Hernández ha caracterizado positivamente como «simbiosis neopopulista y civil» (2003: 27), mientras que para GarcíaPosada «la consigna o el lema político arruinan las Canciones de la paz» ${ }^{2}$.

También es cierto que Canciones de la paz parece marcar una frontera, un término a partir del cual Rejano ya no va a cultivar el tono menor de manera sistemática, y se va a decidir por el arte mayor, el himno y la elegía, que culminará en el Libro de los homenajes y los libros póstumos La tarde y Elegías mexicanas.

A la vista de los datos anteriores, se puede decir que la estética popular y la canción menor tienen un lugar importante en la creación de nuestro autor entre 1944 y 1954. Señalemos, a efectos de cómputo, que Canciones de la paz debió escribirse al menos un año antes de su fecha de publicación, pues en el periódico quincenal España y la paz (órgano del Movimiento por la Paz) de 15/04/1953 (p. 8), Rejano adelanta 7 poemas: «El labrador», «La novia», «Azahar», «La abeja», «Canción para los niños», «La paloma de la paz» y «Primavera de 1951 en España», sin variantes con respecto a la edición de 1955,

\footnotetext{
${ }^{2}$ García-Posada, Miguel. «La mirada del hombre. Nueva suma poética (1943-1976)», ABC literario. 14 de mayo de 1988, p. 55.
} 
y en el mismo orden en que aparecerán en el libro, lo que quiere decir que en 1953 Canciones estaba ya prácticamente acabado y organizado. Pero nos podemos remontar más atrás, pues la «Canción del Guadalquivir», que aparece por primera vez en Canciones sin fechar, cuando en 1975 pasa a ser la tercera parte de «Coloquio de los ríos (fragmentos)» de Constelación menor, la tenemos fechada en 1945, lo que quiere decir que probablemente Rejano estuviera por ese tiempo escribiendo canciones de corte neopopular en la estela de El Genil y los olivos sin un plan editorial concreto, algunas de las cuales acabarán formando parte de Canciones, junto con otros poemas más comprometidos escritos al calor de las circunstancias que describiré a continuación.

Lo que hizo que la producción poética de Rejano del momento cristalizara como lo hizo en Canciones fue el contexto histórico y la implicación del autor en el Movimiento Mundial por la Paz.

La editorial en que ve la luz el libro toma nombre del periódico fundado en 1951 en México: España y la paz, con León Felipe como director y con un consejo de redacción formado por: Rafael Alberti, Fernando Benítez, José Bergamín, Luis Buñuel, Alejandro Casona, Pedro Cavia, Francisco Comesaña, José Giral, Heriberto Jara, Manuel Márquez, Ceferino Palencia, Juan Rejano, Wenceslao Roces, Martí Rouret, Manuel Sánchez Arcas, Luis Santullano y Fernando Vázquez Ocaña ${ }^{3}$.

Esta publicación es iniciativa del Consejo Español de la Paz (sección española del Consejo Mundial de la Paz), fundado en 1949 y presidido por José Giral, expresidente del gobierno republicano (Hoyos Puente, 2011). Aunque leemos en su primer editorial que España y la paz no se adscribe a ninguna ideología, sin embargo queda patente su vinculación con la izquierda intelectual y el PCE (basta repasar la lista de redactores) y tiene un decidido carácter antiestadounidense. El mapa que preside la portada del primer número presenta a España encadenada, con un candado en forma de dólar y plagada de banderas estadounidenses. La salida de la revista coincide con el inicio de las aportaciones financieras de EE. UU. al régimen de Franco y con las negociaciones que culminarán con los acuerdos de 1953 entre Franco y Truman para establecer bases militares americanas en la Península.

El antiamericanismo de la publicación, aparte de un sentimiento nacionalista, procede del órgano superior del que dependía, el Consejo Mundial de la Paz, fundado entre 1949 y 1950 desde la órbita soviética para crear un clima de opinión contrario a la expansión de EE. UU. en Europa (son los años del plan Marshall) y en Asia (intervención estadounidense en Corea) y a él se adhirieron muchos intelectuales, casi todos vinculados a partidos comunistas:

\footnotetext{
${ }^{3}$ Los datos de España y la paz, España popular y Frente rojo así como las referencias a papeles inéditos de Rejano están extraídos de la Biblioteca Virtual de Prensa Histórica del Ministerio de Educación, Cultura y Deporte, y de los documentos digitalizados en la página web de la Fundación Juan Rejano.
} 
Picasso, Aragon, Lukács... (Marcou, 1981: 27-41)4. Le Bigot (2006: 502-511) expone brevemente cómo los escritores comunistas se adhirieron activamente y recogieron en sus obras las consignas del Kominform sobre la paz, y nos recuerda los casos de Rejano, Alberti, Neruda, sin olvidar que Blas de Otero publicó Pido la paz y la palabra, en 1955, coetáneo exacto de Canciones de la paz. En vano Rejano tratará en determinado momento de desvincular este movimiento de la influencia soviética:

¿Se puede seguir afirmando que con un conglomerado de seres tan diversos, el Movimiento Mundial de Partidarios de la Paz está hecho para servir a un país, a un partido o a una consigna? (2000: 253).

Que el libro de Rejano se inscribía en este Movimiento lo muestra no solo el hecho de que el sello editorial aparezca con el nombre de la revista, sino que gran parte de su contenido refleja su ideología. El antiimperialismo de Canciones queda bien patente en una de sus secciones: «Canciones epigramáticas», donde se denuncia la discriminación racial, la intervención en Corea, el gangsterismo como forma de organización social y la caza de brujas del senador McCarthy. Igualmente, los oficios que aparecen en la sección «Canciones humanas» inciden en el imaginario proletario de la estética comunista: el labrador, el panadero, el miliciano, el pescador... Sin olvidar que inmediatamente después de su aparición en México se hizo una edición rusa del libro (Hernández y Berrio, 1977: 14).

Por esos años es continua la actividad de Rejano en el Movimiento de la Paz. En 1950 dirige $P a z$, «Boletín de la campaña española contra la bomba atómica». En un «Homenaje a Víctor Hugo en el 150 aniversario de su nacimiento» leído en 1952 relaciona la obra del poeta francés con el movimiento por la paz (Rejano, 2000: 110-120). En España y la paz de 15/05/1953 (p. 3) hay una nota de Adolfo Sánchez Vázquez dando cuenta de un recital de Rejano en la Unión de Intelectuales españoles en México de poemas de Canciones de la paz, obra donde Rejano «se afirma aún más como poeta militante, con las armas de la verdad y de la belleza, al lado de la causa que hoy defienden todos los pueblos».

En la mayoría de sus intervenciones por la Paz Rejano aprovecha para recordar la creciente presencia de EE. UU. en España. De 1952 se conserva mecanografiado un discurso para un acto público del Consejo Español de la Paz, celebrado el día 21 de julio, donde denuncia la venta de España a los americanos a través del pacto Franco-Truman. En una ponencia leída en las Jornadas de la Cultura Española organizadas por la Unión de Intelectuales Españoles en

\footnotetext{
${ }^{4}$ El primer Congreso Mundial de Partidarios de la Paz se celebró en París en abril de 1949. Previamente se había desarrollado en la ciudad polaca de Wiroclaw, entre el 25 y el 28 de agosto de 1948, el Congreso de los Intelectuales en Defensa de la Paz. En ambos encuentros hubo representación española.
} 
México, en 1950, titulada «Deberes de los intelectuales españoles en la hora actual» argumenta que los intelectuales españoles emigrados deben sumarse al Movimiento de la Paz, porque su triunfo supondría el fin del apoyo americano a Franco, que EE. UU. necesita en su estrategia de la Guerra Fría.

En otro Discurso de 21 de julio de 1952 Rejano rechaza gráficamente para los españoles el estilo de vida americano: «No, los españoles no queremos beber cocacola sino cuando nos plazca, ni comer por medio de máquinas, ni adoptar el gangsterismo como fórmula de relación social» (2000: 260), e insiste en un argumento que ya había usado antes:

Y la Sexta Flota de los Estados Unidos maniobra como en aguas propias por las aguas españolas, entrando a su antojo en nuestros puertos, para preparar la ocupación definitiva de los litorales y las bases marítimas de España, adelantándose a la llegada del ejército yanqui de ocupación anunciada por Acheson en unas declaraciones (2000: 261).

Cuando aparece el libro en 1955 se suceden los actos en torno a este movimiento. En España popular (publicación periódica del PCE) de 17/06/1955 se da cuenta de la presentación del libro que tuvo lugar el 10 de junio con la asistencia de varios intelectuales encabezados por José Giral, que se sintió aludido en la canción del abuelo abanderado de la paz. Ahí se indica que el importe de la venta del libro «fue donado por su autor para la campaña de la paz». En esta misma publicación, en 24/06/1955 una breve reseña sobre el libro titulada «Un poeta se abraza con el pueblo», firmada por Gabriel García Narezo, vuelve a informarnos de que el libro nace «al calor que despertó el Congreso de Partidarios de la Paz».

En ese mismo número, en la página de portada y bajo el titular «Jornada Internacional de la Infancia. ¡Paz a los niños!» se nos informa de que la Unión de Mujeres Españolas en México, organizó para conmemorar ese día, una fiesta infantil el 18 de junio en la Casa de España, con guiñol y que

[d]el libro 'Canciones de la Paz', del destacado poeta, nuestro camarada Juan Rejano se recitaron varios poemas de los niños y las madres. A continuación de cada recital, toda la numerosa concurrencia infantil repetía a coro el poema, batiendo palmas y conmoviendo a las madres que les escuchaban, pues en los bellos versos de Rejano se reflejan sus más caros anhelos maternales.

Previamente, el 16/03/1952, había aparecido en El Nacional en su sección habitual de opinión «Señales» un artículo en el que Rejano relaciona el mundo de la infancia con la injusticia y la denuncia social, titulado «Hablemos un poco de los niños» a propósito de la próxima celebración en Viena de la Conferencia Internacional para la Defensa de la Infancia. Se trata de una llamada de atención sobre la condición de los niños españoles bajo el régimen de Franco: desnutridos, enfermos, maltratados; imagen de la infancia que no está muy lejos de la que presenta en Canciones, donde los niños andan continuamente amenazados por la guerra y el desastre. 
Teresa Hernández contextualiza, sin embargo, la composición de este libro en un giro de las políticas del Partido Comunista hacia un «proyecto de reconciliación nacional» (2003: 51):

Además, al poeta — corre el año 1955- no le quedan apenas energías ni recuerda afrentas recientes del adversario para seguir cantando a los dinamiteros y a la resistencia. (...) Planteada la nueva estrategia no es difícil imaginar — sobre todo a la vista de los resultados artísticos- que se apresuró a servirla con el mejor entusiasmo e intuición, con esa rara capacidad de sincero convencimiento para hacer suyas las causas que le dictaban (2003: 55).

Dos cosas quedan claras de estos datos: que el libro toma forma en torno a un proyecto político e ideológico, hasta el punto de que su composición puede verse casi como un «imperativo» del Partido no solo como arma de propaganda sino también como expediente recaudatorio toda vez que tenemos constancia de que las ventas del libro fueron a parar al movimiento por la paz; y que, a pesar de ello, la publicación iba dirigida a un tipo de público muy definido: los niños, que participaron activamente en recitados de poemas.

Tenemos, así, una tensión más que se añade a la antes señalada entre el tono menor y popular del libro y su contenido militante: la del carácter de literatura infantil, compatible, de nuevo, con el tono menor, pero en conflicto con el carácter adoctrinador, por no decir político, del contenido.

Que el libro tiene un destinatario explícitamente infantil queda claro ya en la dedicatoria, escrita desde la perspectiva del hijo: «A la memoria de mi padre, muerto más allá del mar y de mis brazos». Y en ello insiste en la pequeña nota introductoria: «Canciones — si ello fuere posible — para que las canten los niños. (¡Si ello fuera posible!) Y los hombres también, en silencio, dentro de su corazón. Tal su más íntimo anhelo».

La relación de la infancia con la nostalgia de la patria perdida y el tono menor es una constante en los poetas del exilio, como ocurre en Prados, y como bien señala Carlos Blanco Aguinaga:

En primer lugar, y por supuesto, esa 'patria' estaba para todos aquellos poetas en el recuerdo idealizado y esquemático de una niñez y primera adolescencia que, a grandes rasgos y tomando en consideración las diferencias de edad de los de la generación del 27, transcurre entre 1900 y, digamos, 1918 (2006: 75).

Rejano ya había relacionado nostalgia de la patria y niñez en la nota que encabeza El Genil y los olivos:

Nacieron estas canciones, que agrupo con el título de El Genil y los olivos, por una necesidad de aliviar el alma de tanto y tanto recuerdo como la embriaga, en esta lejanía amarga de España. Las publico, ahora, como homenaje de fidelidad a las horas de mi niñez y mi adolescencia. (...) Es posible, también, que en otros [oídos], suene a estribillo de coro infantil, repetido en la tarde de provinciales silencios. Ni una ni otra cosa contrarían mi propósito (2003: 175). 
Aunque el libro trata de mantener el tono y la estética de la canción (no siempre infantil), da cabida en ocasiones al verso libre mayor y a algunas complejidades temáticas y sobre todo ideológicas que lo alejan de lo genuinamente popular y menor, que daba coherencia a El Genil y los olivos.

\section{CoRrecCIONES DE CANCIONES DE LA PAZ}

Como se ha anunciado, Canciones de la paz es el libro de Rejano que más cambios sufre en el periplo editorial, y cambios bastante drásticos. Cuando el poeta realiza la primera gran antología con vocación de poesías completas: Alas de tierra (1975), el poemario ha desaparecido como tal, y algunos de sus poemas han ido a parar a otros libros. Poco antes de morir, Rejano revisa este material y deja dispuesta para la impresión la última entrega en la que pudo intervenir, que bajo el título La mirada del hombre, y con estudio introductorio de Aurora de Albornoz, verá la luz en Madrid en 1978 (ed. Casa de Campo) y será reeditado en 1988. En esta «Nueva Suma poética», Canciones de la paz, vuelve a aparecer entre los libros de Rejano, pero con ciertas mutilaciones y el traslado de algunos poemas a otros libros. En muy poco tiempo, pues, Rejano ha repudiado y vuelto a aceptar este libro y, en definitiva, lo ha modificado notablemente. Debemos preguntarnos, entonces, qué dudas albergaba sobre su pertinencia, la adecuación de su mensaje y su entidad como poemario $^{5}$.

En Alas encontramos la siguiente advertencia inicial:

Reúno en estas páginas mis libros de poemas aparecidos en México, de 1943 a 1966, salvo ciertos fragmentos de algunos de ellos que por razones de carácter selectivo he considerado necesario excluir. Algunos de esos libros han desaparecidos ahora como tales y han entrado a formar parte de otros, previa selección también de sus composiciones. He corregido, además, algunos poemas, y a otros los he cambiado de lugar para situarlos en una atmósfera más conveniente. Por último, incluyo aquí varios grupos de canciones y pequeños poemas que habían permanecido inéditos, así como otras composiciones sólo publicadas en revistas literarias hasta 1973 (1975: 5).

Hasta llegar a la redacción definitiva de esta explicación, Rejano realizó varios borradores en los que resulta patente su vacilación a la hora de explicar la eliminación y manipulación de algunos libros. Todos los borradores coinciden en señalar que ha dejado de incluir algunos poemarios por su «índole civil o heroica» con el fin de dar mayor unidad temática al libro. Ello puede explicar la eliminación de Canciones pero no da cuenta de la inclusión de «Oda española» dedicada a Dolores Ibárruri, La Pasionaria, o el Libro de

\footnotetext{
${ }^{5}$ A partir de ahora abreviaré así: Canciones por Canciones de la paz (1955); Alas por Alas de tierra; Mirada por La mirada del hombre; y Poesía por Poesía completa.
} 
los homenajes, con bastantes ingredientes políticos, o el más directamente heroico Fulgor violento, título dado al que originalmente llevaba el de Víspera heroica. Canto a las guerrillas de España.

Pero más revelador resulta que en la mayoría de estos borradores en lugar de «Algunos de esos libros [eliminados]» encontramos la siguiente redacción:

Uno [tachado: 'alguno'] de los libros en que se basa esta antología ha desaparecido ahora como tal, y sus composiciones, sometidas también a rigurosa selección, han entrado a formar parte de otros libros.

Este «uno» de los libros no puede ser otro que Canciones, el único suprimido como tal. Resulta paradójico que Rejano afirme simultáneamente que el desaparecido es «básico» para la antología.

La incomodidad de Rejano con su decisión de 1975 se aprecia una vez más cuando en la nota que añade a Mirada (1988: 31), en lugar de las razones aducidas entonces, alega ahora falta de espacio:

Fuera de la edición [de 1975] quedaron, por razones de espacio, buen número de composiciones, incluso dos libros completos: Oda española y Canciones, que ahora se incluyen en ésta, el primero rigurosamente corregido, y el segundo sometido a una exigente selección.

Esta afirmación tampoco es cierta del todo, pues Oda española no desapareció entera de Alas sino que se recogió fragmentariamente.

\section{a) Poemas eliminados}

Vamos a empezar, pues, estudiando los poemas eliminados por completo, los que aparecieron en la edición original de 1955 y nunca más se volvieron a editar en ninguna de las recopilaciones.

La sección «Canciones epigramáticas» desaparece entera, y de «Otras canciones» solo se rescata en Mirada (no en Alas) el poema «En todas las azoteas», ubicado en otra sección. La razón del borrado de la primera sección resulta evidente toda vez que se trata del conjunto más ocasional del libro, ligado a las circunstancias concretas del contexto en que nació: su antiimperialismo y antiamericanismo combativo invalida a estos poemas para sobrevivir como poesía más allá del motivo que los hizo componer.

«Otras canciones» tiene como debilidad su carácter ecléctico: carece de un motivo que le dé unidad como al resto de las secciones del libro. Además, su tono es más sombrío y su mensaje en ocasiones bastante simple y directo. En el primer poema, por ejemplo, se contrastan un paisaje primaveral (clavellinas, trigales, amapolas) y una casa en paz («morada / de unas gentes candorosas») con la posibilidad de su destrucción por una bomba (probablemente atómica): «un negro embudo de tierra», «un sucio montón de escombros». El 
cierre del poema carece de lirismo: «Hermano: yo amo la vida. / Vente a defender la paz». Esto nos da una idea del tono de la sección, que simplifica en exceso el conflicto y no lo compensa con una mayor elevación lírica. Rejano rescata el último poema: «En todas las azoteas», porque, en mi opinión, aunque sigue teniendo un mensaje demasiado directo, sin embargo está elaborado con la técnica eminentemente lírica del paralelismo, heredada de la poesía popular. Todas las estrofas reproducen la misma estructura: En todo/as + sust. / adj. + sust. de paz / (sust. + verbo + complem. / variable). Copio la primera como ejemplo: «En todas las azoteas, / celestes gritos de paz. / (El aire mueve los sueños / como una ronda de niños)».

Paso a listar ahora los textos del resto de las secciones que desaparecen de todas las compilaciones. De «Canciones humanas», dedicadas principalmente a oficios:

- la 3: «La artesa, la blanca harina», sobre el panadero, quizá por las connotaciones eucarísticas que contiene;

- la 5: «Ya se han ido los niños», en la que se nos presenta a un maestro de escuela meditando frente al crepúsculo tras las partida de los alumnos, es un poema de corte machadiano que responde a una estética impresionista más que a la de la canción, pero acaba con un mensaje demasiado sombrío y directo sobre el futuro de los niños en la guerra, que rompe a la vez la atmósfera intimista y reflexiva inicial;

- la 7: «Soldado», eliminada probablemente porque habla en términos bastantes crudos de guerra y muerte, y contiene un mensaje más directamente ideológico al introducir la figura del banquero que busca la guerra por su propio beneficio;

- la 8: «Con tierra y agua construyes», en que se invita al albañil a que baje del andamio porque lo reclama la paz, y se cierra con una ambigüedad: «con la palabra también / pueden levantarse muros, / albañil», donde no sabemos si se pretende que el albañil sustituya sus herramientas por la palabra o si se considera que la palabra es un medio de aislamiento y separación de los hombres;

- la 10: «De sol a sol, / jornalero», con un mensaje claramente ideológico sobre la relación trabajador-amo y la promesa de la posesión final de la tierra trabajada;

- la 12: «Estudiante» presenta un panorama demasiado negativo y desalentador en que la juventud, en caso de guerra, «como un arbolillo tierno / caerá bajo la tormenta»;

- la 14: «Poeta» es un llamamiento a los poetas para que se impliquen, dejen de cantar su «yo» y no se pierdan en la «fronda verbal»; actitud que contradice la práctica del propio Rejano cuando realiza la compilación.

De «Canciones vegetales»: la 6, «Venerable laurel», probablemente por el ingrediente que tiene de invectiva contra quien ha servido siempre como símbolo de las hazañas bélicas. 
De «Canciones que vuelan»: la 3, «Oh, búho silencioso», y la 6: «Vete, cuervo», por ser ambos animales ominosos, y contener mensajes negativos. Al búho se le contrapone la figura del «traficante atómico».

De «Canciones para los niños»: la 1, «Vámonos a la pradera», y la 3: «(Nana para que el niño no se duerma)», ambas en exceso dramáticas y sombrías, pues pasa en ellas a primer plano el terror y destrucción de la guerra, empañando el anhelo de paz. En la segunda, de hecho, el papel amedrentador que jugaba el «coco» en las nanas es asignado ahora a la guerra y la muerte.

De «La paloma de la paz»:

- la 3: «Dulce paloma», quizá por su carácter más ideológico al hablar del «pueblo»;

— la 6: «Pétalo caliente», es la única de la sección en que no se hace mención explícita de la paloma;

- la 9: «(A Picasso)», que tampoco habla de la paloma de la paz, sino de su creador.

De «Canciones de España»:

- la 2: «(Primavera de 1951)», por su carácter más directamente circunstanciado y acusador: «España no irá a la hoguera / que alimenta el homicida», «¡Fuera los yanquis de España!»;

- la 5: «Contigo, la verde espiga», quizá porque tiene menos de canción que el resto;

- la 6: «La bandera verde y blanca», breve alegoría sobre los colores de la bandera de Andalucía;

- la 7: «Obrero, tú eres la patria», por su carácter claramente ideológico;

- la 10: «En el cielo de Castilla», que trata también del pueblo que «se yergue ante el invasor»;

- la 11: «Al guerrillero, el fusil», una justificación de la guerra como medio para alcanzar la paz.

Un simple recuento nos dice que de los 72 poemas del libro original se han conservado solo 40, es decir el 55,5\%, y han desaparecido, por tanto, casi la mitad de las composiciones, lo que supone una drástica reducción, y más si tenemos en cuenta la reubicación de los poemas en secciones de otros libros.

Un primer balance parece indicar que Rejano ha eliminado los poemas y secciones enteras que más directamente dependían de las circunstancias políticas e ideológicas que dieron nacimiento al libro, los de más calado político y los que hacían acusaciones o lanzaban mensajes más directos, en consonancia con la advertencia que hacía sobre su selección en Alas. También ha considerado inapropiados todos aquellos poemas que sin ser directamente políticos presentaban aspectos negativos, intentando concienciar a la paz por medio de la presentación de los horrores y sufrimientos de la guerra. En menor medida parece haber tenido en cuenta el poeta para la supresión total aspectos estilísticos o de coherencia formal y temática. 


\section{b) Cambios de ubicación}

Vamos a examinar ahora los cambios de ubicación que experimentan los poemas.

La sección «Canciones de España», con las eliminaciones que hemos señalado, se traslada, en Alas y Mirada, casi entera al libro Constelación menor (1950), formando así una nueva sección de este volumen que no existía en el original. «Canción del Guadalquivir», sin embargo, pasa a ser la tercera parte del poema «Coloquio de los ríos (fragmentos)» que abre Constelación menor.

El único poema de esta sección que no acaba en Constelación menor es «Leve bruma de la tarde», que pasa a formar la parte cuarta de «Nuevos motivos del Genil» de El río y la paloma (1961). Por su parte, «En aquel sotillo» se convierte en el número 6 de la sección «La paloma de la paz» dentro de Canciones a partir de Mirada.

Comprobamos, así, que la sección «Canciones de España» desaparece en el libro y va a parar como tal sección (y la mayoría de sus poemas) a Constelación menor. Eso se explica porque este libro era muy breve, con apenas 30 páginas, y difícilmente justificable en la estética «menor» que anuncia su título, pues de ella solo tenía unas soleares a Alfonso Reyes, tres canciones antiguas y tres nanas. Con la incorporación de «Canciones de España» y de un cancionerillo de «Córdoba del trópico» fechado en 1949 el volumen adquiere más entidad y justifica mejor su título.

El otro gran movimiento que realiza Rejano en Alas es llevar los poemas de las demás secciones que creía salvables de Canciones a una sección añadida e inexistente en el original de El río y la paloma (1961) titulada «La paloma de la paz». Esta nueva sección acoge cuatro de las «Canciones vegetales» («El chopo», «Por los caminos de marzo», «Arquitectura» y «Del olivo proverbial»); dos de las «Canciones que vuelan» («Tu nido, golondrina» $\mathrm{y}$ «Un parpadeo en el aire»; una de las «Canciones para los niños» («Dompedros y donjuanes»); y tres poemas de «La paloma de la paz» («Eres como un suspiro», «En cada corazón» y «Se fue la noche»). Todos estos textos volverán a sus antiguas secciones cuando en Mirada se recupere Canciones como volumen independiente.

Como hace con Constelación menor, parece que en 1975 Rejano quiere dotar de más entidad a El río y la paloma, que originalmente constaba de 28 páginas, añadiéndole los poemas provenientes de Canciones y además justificando de nuevo la presencia de la «paloma» del título. Lo que ocurre es que, al contrario que Constelación menor, El río y la paloma es un poemario de carácter elegiaco y grave, lo que provoca que su unidad se desvirtúe al añadirle todas estas composiciones más breves y ligeras. Eso hace que mientras que lo trasvasado a Constelación menor se mantenga en sucesivas compilaciones, lo vertido en El río y la paloma vuelve a su lugar a partir de Mirada.

El poema inicial «Canción que llama a tu puerta» pasa, en Alas y las siguientes compilaciones, al Libro de los homenajes (1961) con el título «A 
Pablo Picasso, que me envió una paloma (1953). Canción de Paz», un traslado bastante razonable teniendo en cuenta que es un poema de amplio aliento, que nada tiene de canción y que se parece más a los poemas celebrativos de su nueva ubicación.

\section{c) Variantes textuales}

Ahora debemos centrarnos en las variantes textuales para completar el análisis.

Algunas variantes son puramente gramaticales, de puntuación o de presentación tipográfica. Por lo general, en las ediciones posteriores a Canciones se ha evitado el sangrado que aparecía en las estrofas originales, con lo que la presentación gráfica se hace más homogénea. La única excepción es el poema «El niño juega en el césped», en que los dos versos que hacen de estribillo y que empiezan con la anáfora «Paz» están sangrados con respecto a las otras estrofas, cosa que no ocurre en Canciones con la segunda aparición del estribillo, probablemente por errata.

Las variantes que suponen cambios mayores parecen responder a dos motivos. El primero es la eliminación de la palabra «paz» en varias ocasiones quizá por demasiado recurrente a lo largo del poemario. El poema «Abre los ojos y mira» (n. ${ }^{\circ} 3$ de «Canciones de España») tiene como último verso en todas las compilaciones: «te espera mi corazón», en lugar del original: «tendrá paz tu corazón», final más acorde con el carácter amoroso de todo el poema.

Lo mismo ocurre con el título del poema 4 de «Canciones de España» que pasa de ser «(Recuerdo de adolescencia y paz)» a solo «Recuerdo de adolescencia» en todas las compilaciones. En el poema «En todas las azoteas» ( $7 \mathrm{de}$ «Otras canciones») el verso 8 dice: «por la luz una bandera)», en lugar del original: «por la paz una bandera)». Y en «Leve bruma de la tarde» (8 de «Canciones de España») también encontramos «Entre mis manos, las sombras», donde el original decía: «¿Qué paz profunda en mis manos!», lo que da un tono más existencial al poema al tiempo que elimina la mención de la paz.

Curiosamente el poema «(El chopo)» $(3$ de «Canciones vegetales») que suprime, en Alas, en el verso 23 una mención a la paz, vuelve a su estado original a partir de Mirada: «¿Qué recatado en tu paz!».

Las demás variantes suponen cambios estilísticos.

En el poema «Se fue la noche» (n. ${ }^{\circ} 8$ de «La paloma de la paz»), en Alas, los dos versos finales: «QQué buenos días, paloma, / se me entran por el alma!», son sustituidos por «iQué terrenal alborozo, / paloma, nace en mi alma!», mucho más interesante que la versión original, al sustituir el anodino saludo «buenos días» por un sintagma con más fuerza: «terrenal alborozo» y sintetizar la acción en «nacer» en lugar del más pesado: «se me entran»; sin embargo, en la versión de Mirada y Poesía el poema vuelve a su forma original. 
Del poema «Tu nido, golondrina» (n. ${ }^{\circ} 4$ de «Canciones que vuelan») en Alas leemos: «Olvídate / del olvido» en lugar de «olvídate, golondrina, / del olvido», y «Tu nido, golondrina, / ¿dónde tu nido?» en lugar de «Tu nido, golondrina, / cuida tu nido», pero lo más significativo es que se suprime entera la estrofa: «Que la tormenta amenaza. / Que tus hijos / pueden morir bajo el rayo / lívido.», supresión que está en la línea de evitar lo más sombrío y trágico del poemario. En Mirada y Poesía el único cambio que se mantiene es la supresión de la estrofa, el resto vuelve a su versión original.

De «El niño juega en el césped» (n. ${ }^{\circ} .6$ de «Canciones humanas») se elimina igualmente una estrofa entera en Mirada y en Poesía: «-Dime, nubarrón sombrío, / ¿descenderás tus metrallas / sobre esta dulce cabeza, / tan inocente, tan cándida? / ¿No se detendrá tu furia? / ante su mirada?». Se trata, de nuevo, de evitar lo sombrío.

En «Chiquito te viene el campo» (n. ${ }^{\circ} 1$ de «Canciones que vuelan») se suprimen en Mirada los dos últimos versos: «La alegría siempre nueva / de vivir», y el poema acaba con la estrofa: «Construir, / no destruir, / dice al aire tu bandera.», de una manera más coherente con el resto del poema, pues el tema es la labor de la abeja para levantar su colmena.

En «La luna se ha puesto» (n. ${ }^{\circ} 2$ de «Canciones para los niños») los dos últimos versos dicen en Mirada y Poesía: «La luna brilla en el cielo / por la paz», en lugar de «La luna firma en el cielo / por la paz», de carácter más comprometido y con una metáfora un tanto dudosa.

En el poema «A la rueda rueda» ( . $^{\circ} 6$ de «Canciones para los niños») el verso 1 en Mirada aparece sin la repetición, que se restituye en Poesía; y los dos últimos versos: «Niños de la tierra, / defended la paz», se sustituyen en ambas ediciones por: «Paz para los niños. / Paz.», con un mensaje menos combativo.

En «(La novia)», leemos, en Mirada y Poesía, en el verso 5, «se le nubla el corazón», en lugar de «se le anubla el corazón», en aras de la simplicidad.

En el poema «Tu pico» (n. ${ }^{\circ} 2$ de «La paloma de la paz») se lee en 1955: «todas las albas futuras / alumbran eu frente» en sus dos últimos versos. Entendemos que es una errata, en que el cajista ha invertido la «n» que debería leerse «en», lo que nos da idea de que la paz está todavía por alcanzar. Sin embargo, en Mirada y Poesía el verso aparece corregido en otro sentido: «alumbran tu frente», como si la paz ya estuviera conseguida.

En cuanto a la nota introductoria de 1955, se reproduce en Mirada y Poesía con la supresión de los dos últimos párrafos. Probablemente se prescinde del cuarto párrafo porque aludía a las circunstancias de composición en el contexto político de la época, ya irrelevante hacia 1976: «la esperanza en la paz que estamos conquistando quienes, por encima de mares y continentes, nos tendemos las manos y el pensamiento». El último párrafo, muy breve, apenas aportaba nada a lo ya dicho: «He ahí la sola —y apasionada - melodía escondida en estas páginas». 
La edición de Poesía sigue en casi todo, como hemos visto, la de Mirada, con alguna curiosa excepción que nos indica que la editora ha tenido delante la edición original de 1955. Por ejemplo, en «La encina» (11 de «Canciones vegetales»), la errata de 1955: «Si todo canta / en el viento, / la fuente, / al [sic] ave, el insecto» (vv. 15-18), que aparece corregida en Mirada vuelve a su error original en Poesía.

En el ámbito de las variantes, pues, comprobamos una tendencia a eliminar repeticiones y alusiones demasiado crueles y sombrías, y a simplificar y hacer más clara la expresión.

\section{CONCLUSIONES E HIPÓTESIS}

A la luz del análisis anterior podemos aventurar algunas hipótesis que den cuenta de las vacilaciones y, en cierto modo, la incomodidad que sentía Rejano ante Canciones.

Creo que en la raíz de este sentimiento está el hecho de que el libro surgió ligado a circunstancias políticas e históricas que pesaron más que los elementos puramente literarios. Rejano, por esos años y por su compromiso con el Partido Comunista y con el Movimiento por la Paz, se vio de alguna manera obligado (con una imposición probablemente interior y gustosamente asumida) a dedicar una obra a la lucha por la paz mundial, de manera que reunió poemas de carácter popular que venía escribiendo (sabemos que el más temprano del libro está fechado en 1945), escribió otros nuevos para la ocasión, se acercó al mundo infantil, cosa que antes nunca había hecho, y formó un poemario que, cuando hace su propia selección en 1975 , ve que no tiene toda la unidad que debería y que lo lastra un mensaje en ocasiones muy circunstanciado. Por esas fechas, además, Rejano había pasado a ser crítico con el dirigismo cultural, como muestra la respuesta que da a una pregunta acerca de su impresión sobre los países con regímenes comunistas que había visitado:

También he visto cosas, sobre todo en el terreno de la cultura, con las que no estoy de acuerdo (Hernández de León-Portilla, 2003: 314).

Es evidente que el poeta ha sufrido una evolución, y no ve en 1975 las cosas como las veía en los años 50:

Con el paso de los años, la melancolía de la distancia impone sus acordes, más mesurados y nostálgicos que agresivos, a la voz distante de la poesía del desterrado. Es la voz del ausente más que el canto del desterrado, la que se abre paso en los años finales del decenio de 1950 (Hernández, 2003: 40).

Por otra parte, Rejano había reservado siempre la estética menor y de canción para transmitir contenidos de emoción sencilla y de nostalgia de la patria, pero en Canciones pone esta estética al servicio de un contenido que no 
le convenía, y más cuando comprobamos, como hemos hecho, que en muchas ocasiones el poemario, en lugar de una exaltación y celebración de la paz, se convierte en un elenco de horrores traídos por la guerra. Por no mencionar que muchas veces el tono de sugerencia que debe tener la estética popular y la canción se ve contradicho por la consigna directamente expresada. GarcíaPosada, que cree que Rejano da lo mejor de sí en el verso breve, escribe:

[c]uando se tradujo en fórmulas subordinadas a las circunstancias históricas y políticas, el resultado no fue beneficioso para él. Sucede así en buena parte del libro citado [Memoria en llamas]; en Fulgor violento, canto a las guerrillas antifranquistas (1947); en Oda española, homenaje a Dolores Ibárruri (1949); en Canciones de la paz (1955) [... $]^{6}$.

Se une a ello que Rejano parece no entender del todo la estética infantil. Se diría que tiene un concepto de la literatura para niños en términos de adoctrinamiento y no de disfrute del lenguaje y de imaginación. En plena guerra encontramos un número sin fechar de Frente rojo en el que Rejano da cuenta de las novedades de literatura infantil de la editorial Estrella, en un artículo titulado «Ética y poética. Libros para los niños». Aquí el autor deja clara la vinculación entre literatura infantil y conciencia. Habla de lo difícil que es expresar problemas complejos en términos sencillos y sugerentes, de «la obligación de llegar a una coalición de la ética y la poética, puesta al servicio de la difícil simplicidad», y, al denunciar la pobreza de la tradición cuentística española, indica que «no se ha hecho llegar a los niños los grandes mitos, las leyendas y aventuras fabulosas, vertidos en fáciles moldes y explicados a la luz de un racionalismo simplificador, encantador».

Con todo, el saldo final no es negativo. Rejano salvó, con buen criterio, las composiciones más válidas de su poemario, que hoy podemos seguir disfrutando, aunque el libro no tenga ya la forma primitiva.

ANEXO:

TABLA COMPARATIVA DE LAS PRINCIPALES EDICIONES DE CANCIONES DE LA PAZ

\begin{tabular}{|l|l|l|}
\hline Canciones de la paz (1955) & Alas de tierra (1975) & $\begin{array}{l}\text { La mirada del hombre (1988) } \\
\text { Poesía completa (2003) }\end{array}$ \\
\hline $\begin{array}{l}\text { CANCIÓN QUE LLAMA A TU } \\
\text { PUERTA } \\
\text { 'Una sílaba. / Una sílaba sola' }\end{array}$ & $\begin{array}{l}\text { Libro de los homenajes (1961) } \\
\text { 'A Pablo Picasso, que me envió una } \\
\text { paloma (1953) Canción de Paz' }\end{array}$ & $\begin{array}{l}\text { Libro de los homenajes (1961). } \\
\text { 'A Pablo Picasso, que me envió una } \\
\text { paloma (1953) Canción de paz'. }\end{array}$ \\
\hline $\begin{array}{l}\text { CANCIONES HUMANAS } \\
\text { 1'El labrador / mira' }\end{array}$ & & $\begin{array}{l}\text { CANCIONES HUMANAS } \\
\text { 2.- 'El labrador / mira' }\end{array}$ \\
\hline
\end{tabular}

${ }^{6}$ Vid. referencia completa supra nota 2. 


\begin{tabular}{|c|c|c|}
\hline $\begin{array}{l}\text { 2'Madre, / tu llanto no basta' } \\
\text { 3'La artesa, la blanca harina' } \\
\text { 4'Marinero, / ni en el mar' } \\
\text { 5'Ya se han ido los niños' } \\
\text { 6'El niño juega en el césped' } \\
\text { 7'Soldado, / que tu armamento' } \\
\text { 8'Con tierra y agua construyes' } \\
\text { 9(La novia) 'Solo de pensarlo' } \\
\text { 10'De sol a sol, / jornalero' } \\
\text { 11'Ay, el abuelo, el abuelo' } \\
\text { 12'Estudiante,' } \\
\text { 13'Junto al telar / -ritmo de ola-' } \\
\text { 14'Poeta: / la palabra y nada más' }\end{array}$ & & $\begin{array}{l}\text { 1.- 'Madre, / tu llanto no basta' } \\
\text { 3.- 'Marinero, / ni en el mar' } \\
\text { 4.- 'El niño juega en el césped' } \\
\text { 5.- (La novia) 'Sólo de pensarlo,' } \\
\text { 6.- 'iAy, el abuelo, el abuelo!' } \\
\text { 7.- 'Junto al telar' }\end{array}$ \\
\hline $\begin{array}{l}\text { CANCIONES VEGETALES } \\
\text { 1'A la flor del naranjal' } \\
\text { 2'Jazmín / frío, / nocturno clarín' } \\
\text { 3(El chopo) 'Solo, / junto al río' } \\
\text { 4'Por los caminos de marzo' } \\
\text { 5'Arquitectura / y aroma' } \\
\text { 6'Venerable laurel' } \\
\text { 7'Grano a grano / te madura' } \\
\text { 8'Del olivo proverbial' } \\
\text { 9'Tan alto, tan alto, pino' } \\
\text { 10'A la orillita del río' } \\
\text { 11(La encina) 'Bajo tu sombra' }\end{array}$ & $\begin{array}{l}\text { El río y la paloma. Sección 'La palo- } \\
\text { ma de la paz' } \\
\text { 4.- (El chopo) 'Solo.' } \\
\text { 5.- 'Por los caminos de marzo' } \\
\text { 6.- 'Arquitectura'. } \\
\text { 7.- 'Del olivo proverbial' }\end{array}$ & $\begin{array}{l}\text { CANCIONES VEGETALES } \\
\text { 1.- 'A la flor del naranjal' } \\
\text { 2.- 'Jazmín' } \\
\text { 3.- (El chopo) 'Solo' } \\
\text { 4.- 'Por los caminos de marzo' } \\
\text { 5.- 'Arquitectura / y aroma' } \\
\text { 6.- 'Grano a grano' } \\
\text { 7.- 'Del olivo proverbial' } \\
\text { 8.- 'Tan alto, tan alto, pino' } \\
\text { 9.- 'A la orillita del río' } \\
\text { 10.- (La encina) 'Bajo tu sombra' }\end{array}$ \\
\hline $\begin{array}{l}\text { CANCIONES QUE VUELAN } \\
\text { 1'Chiquito te viene el campo' } \\
\text { 2'Ruiseñor / en los zarzales' } \\
\text { 3'Oh, buho silencioso' } \\
\text { 4'Tu nido, golondrina' } \\
\text { 5(La mariposa) } \\
\text { 6'Vete, cuervo' }\end{array}$ & $\begin{array}{l}\text { El río y la paloma. Sección 'La palo- } \\
\text { ma de la paz' } \\
\text { 8.- 'Tu nido, golondrina' } \\
\text { 9.- (La mariposa) }\end{array}$ & $\begin{array}{l}\text { CANCIONES QUE VUELAN } \\
\text { 1.- 'Chiquito te viene el campo' } \\
\text { 2.- 'Ruiseñor' } \\
\text { 3.- 'Tu nido, golondrina' } \\
\text { 4.- (La mariposa) }\end{array}$ \\
\hline $\begin{array}{l}\text { CANCIONES PARA LOS NIÑOS } \\
\text { 1'Vámonos a la pradera' } \\
\text { 2'La luna se ha puesto' } \\
\text { 3(Nana para que el niño no se duerma) } \\
\text { 4'Vuestros pañuelos, / muchachos' } \\
\text { 5'Dompedros y donjuanes' } \\
\text { 6'A la rueda rueda / del pipirigayo' }\end{array}$ & $\begin{array}{l}\text { El río y la paloma. Sección 'La palo- } \\
\text { ma de la paz' } \\
\text { 10.- 'Dompedros y donjuanes' }\end{array}$ & $\begin{array}{l}\text { CANCIONES PARA LOS NIÑOS } \\
\text { 1.- 'La luna se ha puesto' } \\
\text { 2.- 'Vuestros pañuelos' } \\
\text { 3.- 'Dompedros y donjuanes' } \\
\text { 4.- 'A la rueda' }\end{array}$ \\
\hline $\begin{array}{l}\text { LA PALOMA DE LA PAZ } \\
\text { 1'Eres como un suspiro' } \\
\text { 2'Tu pico / bebe en los labios' } \\
\text { 3'Dulce paloma / del pueblo' } \\
\text { 4'Luna, luna / aceituna' } \\
\text { 5'En cada corazón / tienes un nido' }\end{array}$ & $\begin{array}{l}\text { El río y la paloma. Sección 'La palo- } \\
\text { ma de la paz' } \\
\text { 1.- 'Eres como un suspiro' }\end{array}$ & $\begin{array}{l}\text { LA PALOMA DE LA PAZ } \\
\text { 1.- 'Eres como un suspiro.' } \\
\text { 2.- 'Tu pico' } \\
\text { 3.- 'Luna, luna' } \\
\text { 4.- 'En cada corazón' }\end{array}$ \\
\hline
\end{tabular}




\begin{tabular}{|c|c|c|}
\hline $\begin{array}{l}\text { 6'Pétalo caliente' } \\
\text { 7'La callecita abajo' } \\
\text { 8'Se fue la noche' } \\
\text { 9(A Picasso) 'Aire para el aire' }\end{array}$ & 3.- 'Se fue la noche' & $\begin{array}{l}\text { 5.- 'La callecita abajo' } \\
\text { 8.- 'Se fue la noche' (p. 278) }\end{array}$ \\
\hline $\begin{array}{l}\text { CANCIONES DE ESPAÑA } \\
\text { 1'Junto a la orilla, el pinar' } \\
\text { 2(Primavera de 1951) } \\
\text { 3'Abre los ojos y mira' } \\
\text { 4(Recuerdo de adolescencia y paz) } \\
\text { 5'Contigo, la verde espiga' } \\
\text { 6'La bandera verde y blanca' } \\
\text { 7'Obrero, tú eres la patria' } \\
\text { 8'Leve bruma de la tarde' } \\
\text { 9'En aquel sotillo / al borde del agua' } \\
\text { 10'En el cielo de Castilla' } \\
\text { 11'Al guerrilero, el fusil' } \\
\text { 12(Canción del Guadalquivir) } \\
\text { I.- 'Vengo de un pinar serrano' } \\
\text { II.- 'Entre jara y olivar' }\end{array}$ & $\begin{array}{l}\text { Constelación menor. Sección 'Cancio- } \\
\text { nes de España'. } \\
\text { 1.- 'Junto a la orilla, el pinar' } \\
\text { 2.- 'Abre los ojos y mira: } \\
\text { 3.- (Recuerdo de adolescencia) } \\
\text { El río y la paloma. 'Nuevos motivos } \\
\text { del Genil'. } \\
\text { IV 'Leve bruma de la tarde' } \\
\\
\text { Constelación menor } \\
\text { 'Coloquio de los ríos' } \\
\text { III.- Canción del Guadalquivir }\end{array}$ & $\begin{array}{l}\text { Constelación menor. Sección 'Can- } \\
\text { ciones de España'. } \\
\text { 1.- Junto a la orilla, el pinar } \\
\text { 2.- Abre los ojos y mira: } \\
\text { 3.- (Recuerdo de adolescencia) } \\
\text { El río y la paloma. 'Nuevos motivos } \\
\text { del Genil' } \\
\text { IV 'Leve bruma de la tarde' } \\
\text { 6.- 'En aquel sotillo' (Pasa a la sec- } \\
\text { ción: 'La paloma de la paz') } \\
\\
\text { Constelación menor. } \\
\text { 'Coloquio de los ríos' } \\
\text { III.- 'Canción del Guadalquivir. }\end{array}$ \\
\hline $\begin{array}{l}\text { CANCIONES EPIGRAMÁTICAS } \\
\text { l'Era como una estatua' } \\
\text { 2'Es un país pequeño' } \\
\text { 3'Cayó cuando jugaban' } \\
\text { 4'Senador bisojo' } \\
\text { 5'Mundo viejo, mundo viejo' }\end{array}$ & & \\
\hline $\begin{array}{l}\text { OTRAS CANCIONES } \\
\text { 1'Aquí, donde clavellinas' } \\
\text { 2'Llaman a la puerta y dicen' } \\
\text { 3'La rama pregunta' } \\
\text { 4'En la ciudad / y en el campo' } \\
\text { 5'La madre mece la cuna' } \\
\text { 6'Aquí, bajo este techo' } \\
\text { 7'En todas las azoteas' }\end{array}$ & & $\begin{array}{l}\text { 7.- 'En todas las azoteas' (Pasa a la } \\
\text { sección: 'La paloma de la paz') }\end{array}$ \\
\hline $\begin{array}{l}\text { CANCIÓN DE AMOR PARA EL } \\
\text { DÍA DE LA PAZ } \\
\text { 'Y mañana, amor, mañana' }\end{array}$ & & $\begin{array}{l}\text { CANCIÓN DE AMOR PARA EL } \\
\text { DÍA DE LA PAZ } \\
\text { 'Y mañana, amor, mañana' }\end{array}$ \\
\hline
\end{tabular}




\section{BIBLIOGRAFÍA CITADA}

Albornoz, Aurora de (1988). «La mirada de Juan Rejano», en Juan Rejano, La mirada del hombre. Barcelona: Anthropos, pp. 9-27.

Álvarez, Federico (1991). «Presentación», en Juan Rejano, Antología poética. México: CONACULTA, pp. 13-27.

Aznar Soler, Manuel (2000). «La trayectoria literaria de Juan Rejano», en Juan Rejano, Artículos y ensayos. Sevilla: Renacimiento, pp. 9-30.

Blanco Aguinaga, Carlos (2006). Ensayos sobre la literatura del exilio español. México: El Colegio de México.

Caudet, Francisco (1992). El exilio republicano en México. Las revistas literarias (1939-1971). Madrid: Fundación Banco Exterior.

Hernández, María Teresa (ed.) (2002). Actas del Congreso Internacional «Juan Rejano y el exilio de 1936 en México». Córdoba: Diputación.

Hernández, María Teresa (2003). «Estudio preliminar», en Juan Rejano, Poesía completa. Córdoba: Diputación, pp. 7-90.

Hernández, María Teresa (2006). «Literatura y compromiso en la obra de Juan Rejano», en Manuel Aznar Soler (ed.), Escritores, editoriales y revistas del exilio republicano español de 1939. Sevilla: Renacimiento, pp. 485-500.

Hernández, María Teresa (2008). «Introducción», en Juan Rejano, La tarde y otros poemas. Madrid: Cátedra, pp. 9-88.

Hernández, María Teresa y García Berrio, Antonio (1977). Juan Rejano, poeta del exilio. Salamanca: Universidad.

Hernández de León-Portilla, Ascensión (2003). España desde México. Vida y testimonio de transterrados. Madrid: Algaba ediciones.

Hoyos Puente, Jorge de (2011). «La Guerra Civil en los imaginarios del exilio republicano en México, 1939-1960», Amnis. Revue de civilisation contemporaine Europes/Amériques [en línea]. 2. doi: amnis.revues.org/1499?lang=en

Le Bigot, Claude (2006). «Lectura ideológica del Libro de los homenajes de Juan Rejano», en Manuel Aznar Soler (ed.), Escritores, editoriales y revistas del exilio republicano español de 1939. Sevilla: Renacimiento, pp. 501-514.

Marcou, Lilly (1981). El movimiento comunista internacional desde 1945. Madrid: Siglo XXI.

Rejano, Juan (1975). Alas de tierra. México: UNAM.

Rejano, Juan (1988). La mirada del hombre. Barcelona: Anthropos.

Rejano, Juan (2000). Artículos y ensayos. Sevilla: Renacimiento.

Rejano, Juan (2003). Poesía completa. Córdoba: Diputación.

Rejano, Juan (2008). La tarde y otros poemas. Madrid: Cátedra.

Señales de Juan Rejano (1980). Litoral. Revista de la Poesía y el Pensamiento [número monográfico]. 91-92-93.

Valender, James (ed.) (1993). Ultramar: revista mensual de cultura. México: El Colegio de México.

Fecha de recepción: 16 de octubre de 2013.

Fecha de aceptación: 21 de febrero de 2014. 